\title{
Geologia, geocronologia e litoquímica dos granitos paleoproterozóicos do tipo A no setor setentrional da Província Tocantins
}

\author{
César Lisboa Chaves ${ }^{1}$, Paulo Sergio de Sousa Gorayeb ${ }^{2}$ \& Candido Augusto Veloso Moura ${ }^{2}$
}

\begin{abstract}
Resumo Este trabalho apresenta a caracterização geológica da Suíte Intrusiva Ipueiras em que reúne quatro plutons graníticos (Areias, Ipueiras, Itália, do Carmo) na região de Porto Nacional-Monte do Carmo-Ipueiras, estado do Tocantins, compreendendo a porção norte do Maciço de Goiás no setor setentrional da Província Tocantins. Novos dados petrográficos, litoquímicos, geocronológicos e isotópicos permitiram discriminá-los de outros eventos graníticos presentes na região, tratando-se de granitos subalcalinos de caráter peraluminoso, com assinaturas geoquímicas características de granitos do tipo $\mathrm{A}$. Os estudos geocronológicos $\mathrm{Pb}-\mathrm{Pb}$ em zircão revelaram que os plutons são cronocorrelatos com idades em torno de 2,08 Ga que são representativas da época de cristalização e colocação desses corpos graníticos nos terrenos gnáissicos e granulíticos. As idadesmodelo Sm-Nd, com valores de $\mathrm{T}_{\mathrm{DM}}$ entre 2,19 e 2,15 Ga e $\varepsilon \mathrm{Nd}_{(2,08 \mathrm{Ga}}$ entre $+2,5$ e $+2,9$ indicam curto tempo de residência crustal para a rocha fonte da qual derivou este magmatismo granítico em sua evolução, e os valores de $\varepsilon N d$ indicam contribuição mantélica para a formação desses granitos, caracterizando um domínio juvenil nesta porção do Maciço de Goiás. Os dados revelam a existência de um importante evento de granitogênese de idade paleoproterozóica neste domínio do Maciço de Goiás no setor setentrional da Província Tocantins cujo alojamento dos plutons está relacionado a pulsos magmáticos finais da evolução tectonotermal do evento Transamazônico amplamente distribuído na região.
\end{abstract}

Palavras-chave: Província Tocantins, Maciço de Goiás, Suíte Intrusiva Ipueiras, Granitos tipo-A, Paleoproterozóico.

\begin{abstract}
Geology, geochronology and litochemistry of A-type paleoproterozoic granites in the northern sector of the Tocantins Province. This work presents the geologic characterization of the Ipueiras Intrusive Suite, which comprises four granitic plutons, named do Carmo, Areias, Ipueiras and Itália, located in Goiás Massif, northern sector of the Tocantins Province. New petrographic, litogeochemical, geocronological and isotopic data had allowed to discriminate these plutons of other granites of the region. Lithochemical data showed that they are peraluminous subalkaline granites, with A-type affinity. Single zircon Pb-evaporation data indicate an age of 2,08 $\mathrm{Ga}$ for this magmatism. Sm-Nd $\left(\mathrm{T}_{\mathrm{DM}}\right)$ ages between 2,15 and 2,19 $\mathrm{Ga}$, and positive $\varepsilon \mathrm{Nd}_{(2,08 \mathrm{Ga})}$ values $(+2,5$ to $+2,9)$ for the Areias and Ipueiras granites suggest an origin involving juvenile mantle components. This granitogenesis may be related to the last magmatic pulses of the Transamazonian thermotectonic event, well defined in the region.
\end{abstract}

Keywords: Tocantins Province, Goiás Massif, Ipueiras Intrusive Suíte, A-type paleoproterozoic granites.

INTRODUÇÃO Na porção setentrional da Província Tocantins, região de Palmas-Paraíso do TocantinsPorto Nacional-Ipueiras, o substrato siálico exposto a sudeste do Cinturão Araguaia e sudoeste da Bacia do Parnaíba, compreende terrenos gnáissicos e granulíticos do Paleoproterozóico com idade entre 2, 0 e 2,15 Ga (Gorayeb 1996, Gorayeb et al. 2000b, Arcanjo \& Moura 2000), (Fig. 1). Sobre estes terrenos ocorrem seqüências metassedimentares do Neoproterozóico relacionadas ao Grupo Natividade e plútons graníticos de idade $0,55 \mathrm{Ga}$. Na porção leste ocorrem rochas sedimentares paleozóicas da Bacia do Parnaíba.

A precariedade dos dados geocronológicos e o nível de conhecimento geológico que existia levaram a interpretações diversificadas e conflitantes, particularmente em relação às idades desses granitóides, o que levou a complicações no entendimento do quadro evolutivo discutido para a região.

As primeiras referências a granitóides nessa região estudada são de Barbosa et al. (1966), que denominou esses corpos, informalmente, de Granito Lajeado, posicionando-os no pré-cambriano indiferenciado. Cunha et al. (1981) reuniram, sob a denominação Suíte Plutono-Vulcano Ipueiras, os granitóides e rochas vulcânicas aflorantes na região de Ipueiras. Uma idade convencional pelo método $\mathrm{Rb}-\mathrm{Sr}$ em rocha total de $2.069 \pm 74$ Ma para o Granito Itália foi interpretada por esses autores como a idade de colocação dessa suíte. Em oposição, Costa et al. (1984) reuniram alguns granitóides da região de Porto Nacional, incluindo aqueles citados por Cunha et al. (1981), na Suíte Lajeado, apropriando-se da referência original do Granito Lajeado de 


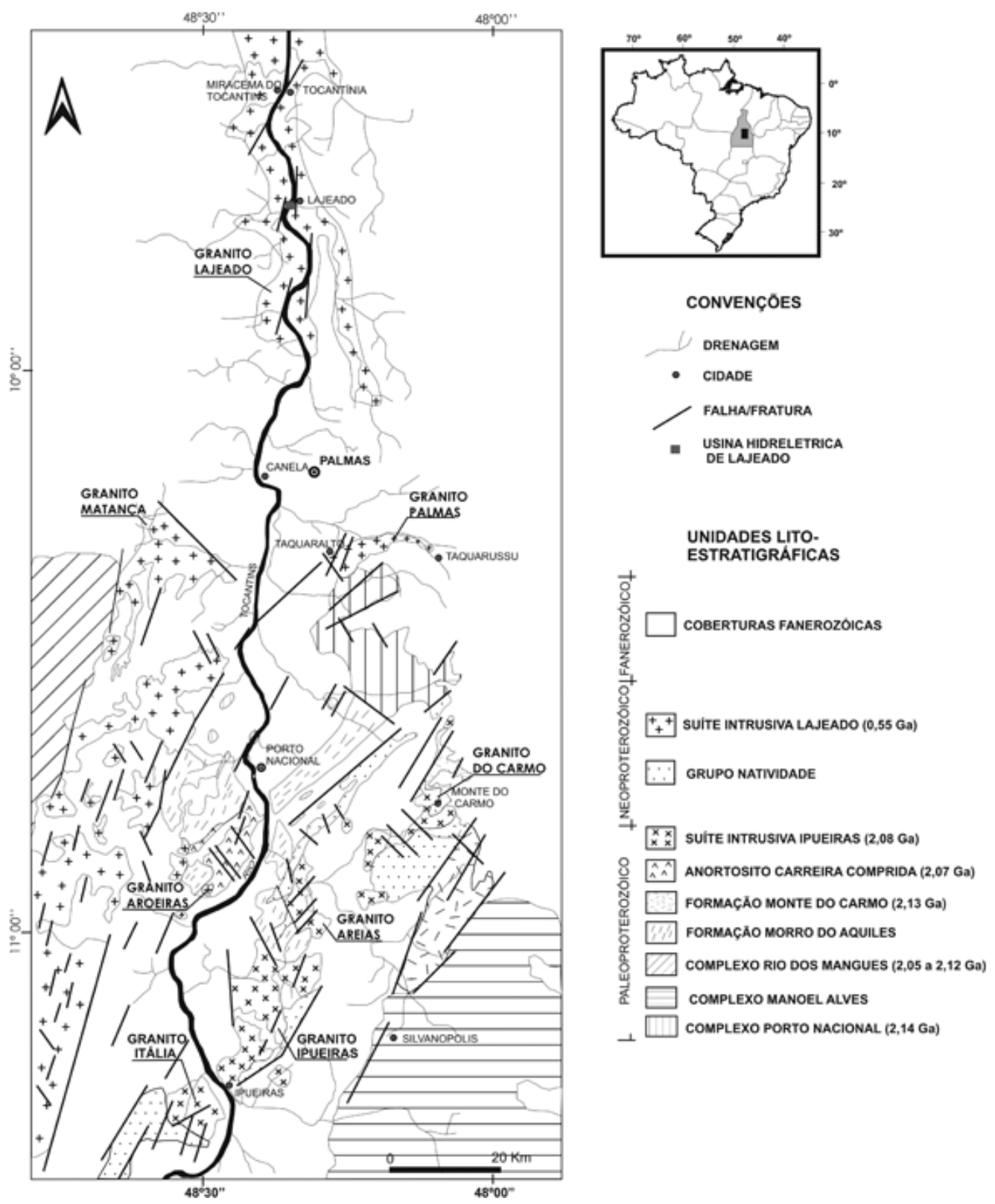

Figura 1 - Mapa geológico da região de Lajeado-Palmas-Porto Nacional-Ipueiras, estado do Tocantins, com destaque aos corpos graníticos ( modificado de Gorayeb 1996 e Chaves 2003).

Barbosa et al. (1966). Com base em uma isócrona $\mathrm{Rb}-$ $\mathrm{Sr}$ em rocha total, construída com amostras de vários corpos localizados entre Porto Nacional e Monte do Carmo, apontaram idade de 1.850 Ma para a colocação crustal dessa suíte. Por outro lado, a existência de outros corpos graníticos, com fortes tramas anisotrópicas (e.g. Granito Matança, Granito Serrote, Granito Cantão), levaram Hasui \& Costa (1990) e Gorayeb (1996) a posicioná-los no Paleoproterozóico, baseando-se em dados estruturais. Idades $\mathrm{Rb}-\mathrm{Sr}$ obtidas no Granito Matança de $469 \pm 10 \mathrm{Ma}$ (Costa 1985) e de $510 \pm 15 \mathrm{Ma}$ (Barradas et al. 1992) foram relacionadas a eventos tectonotermais mais novos que afetaram essa região.

Com o avanço do conhecimento geológico dessa região e a sistematização dessas investigações, no âmbito do Projeto PRONEX/CNPq 103/98UFPA-CG, tem sido possível compreender melhor a evolução do magmatismo granítico dessa região. Dados geocronológicos obtidos em zircão pelo método de evaporação de $\mathrm{Pb}$ e idades modelo $\mathrm{T}_{\mathrm{DM}}$, sustentados pelas investigações tectônicas e petrográficas, levaram a identificação de quatro eventos principais de granitogênese: a) $\sim 2,02 \mathrm{Ga}$ (Granito do Carmo); b) 1,85 Ga (Granito Serrote); c) 0,55 - 0,56 $\mathrm{Ga}$ (Granito Santa Luzia) e 0,54 - 0,56 Ga (granitos Matança, Palmas e Lajeado), (Gorayeb et al. 2000 a, 2001, Moura \& Sousa 2002, Gorayeb \& Moura 2006, 2008).

Apresentam-se neste trabalho os resultados da investigação geológica (petrográfica, litogeoquímica e geocronológica - pelos métodos de evaporação de $\mathrm{Pb}$ em zircão e Sm-Nd em rocha total) realizada nos Granitos do Carmo, Areias, Ipueiras e Itália. 
CONTEXTO GEOLÓGICO A região de PalmasPorto Nacional-Ipueiras, no centro-norte do Estado do Tocantins, é constituída predominantemente por unidades paleoproterozóicas e neoproterozóicas. As unidades mais antigas, do paleoproterozóico são representadas por complexos gnáissicos e granulíticos, seqüências meta-vulcanossedimentares, metagranitóides, plutons anortosíticos e graníticos (Fig. 1).

O Complexo Porto Nacional, de idade 2,14 Ga é formado por granulitos máficos, enderbitos, kinzigitos e raros mobilizados charnockíticos e granada graníticos (Gorayeb 1996, Gorayeb et al. 2000b). O Complexo Rio dos Mangues reúne um conjunto de ortognaisses, de composição tonalítica e granodiorítica, e, restritamente, rochas cálcio-silicáticas, anfibolitos, micaxistos, quartzitos e paragnaisses (Hasui et al. 1984) de idade entre 2,05 a 2,12 Ga (Arcanjo 2002).

O Complexo Manoel Alves (Costa 1985) compreende essencialmente ortognaisses homogêneos de composição tonalítica e metagranitóides sem ainda ter uma definição clara de idade.

A Formação Morro do Aquiles conforme descrita por Gorayeb (1996), é uma seqüência de rochas meta-vulcanossedimentares com micaxistos contendo sillimanita, granada, cordierita e raramente andaluzita. Paragnaisses aluminosos, quartzitos granatíferos, xistos grafitosos, gonditos e metavulcânicas ácidas e básicas, além de intercalações de ortognaisses, anfibolitos e granitóides fazem parte dessa seqüência.

A Formação Monte do Carmo é constituída por conglomerados, arenitos arcoseanos, e sucessões de rochas vulcânicas afetadas por fraco metamorfismo (Gorayeb 1996). As rochas vulcânicas são representadas por riolitos e dacitos e mais raramente andesitos, basaltos, rochas vulcanoclásticas e tufos vítreos fluidais (Gorayeb et al. 1992). Datações em cristais de zircão provenientes de riolitos pelo método de evaporação de $\mathrm{Pb}$ apontam idade de 2,13 Ga para esta unidade (Sachett 1996).

O Anortosito Carreira Comprida, definido por Gorayeb (1996), constitui um plúton isolado, encaixado na Formação Morro do Aquiles, fortemente estruturado pelo cisalhamento dúctil da Zona de Cisalhamento de Porto Nacional. Uma idade de 2,07 Ga foi obtida em cristais de zircão desse anortosito, pelo método de evaporação de $\mathrm{Pb}$, utilizando técnica de filamento simples (Gorayeb \& Moura 2001).

A Suíte Intrusiva Ipueiras, conforme redefinida neste trabalho, reúne pelo menos quatro plútons graníticos denominados de Areias, Ipueiras, Itália e do Carmo estudados neste trabalho.

As unidades do Neoproterozóico são representadas, basicamente, por seqüências metassedimentares e granitos. O Grupo Natividade é constituído, essencialmente, por quartzitos puros e micáceos e raramente filitos, dobrados e metamorfisados em fácies xisto verde. A Suíte Intrusiva Lajeado reúne quatro corpos graníticos principais (Lajeado, Aroeira, Palmas e Matança) com idades em torno de 0,55 Ga (Gorayeb et al. 2001, Chaves 2003, Gorayeb \& Moura 2006).
MÉTODOS ANALíTICOS Para o estudo litogeoquímico foram analisadas 9 amostras dos tipos principais dos granitos Areias, Itália, Ipueiras e do Carmo. Os elementos maiores e traços foram determinados por Fluorescência de Raios-X e os elementos terras raras por espectrometria de emissão atômica com plasma acoplado induzido (ICP-AES), nos laboratórios da empresa Lakefield-Geosol Ltda. As determinações de $\mathrm{Fe}^{2+}$ pelo método de titulação com dicromato de potássio e perda ao fogo por calcinação à $1000^{\circ} \mathrm{C}$, foram realizadas no Laboratório de Análises Químicas do Instituto de Geociências/UFPA.

O método de evaporação de chumbo, em monocristais de zircão ( $\mathrm{Pb}-\mathrm{Pb}$ em zircão), foi utilizado para investigar as idades das rochas graníticas estudadas. Adicionalmente, idades-modelo $\mathrm{Sm}-\mathrm{Nd}$ foram determinadas para estas rochas. Ambas sistemáticas analíticas foram realizadas no Laboratório de Geologia Isotópica da Universidade Federal do Pará (Pará-Iso) utilizando um espectrômetro de massa Finnigan MAT 262.

Os cristais de zircão foram extraídos de aproximadamente $30 \mathrm{~kg}$ de rocha após britagem, moagem, deslamagem, peneiramento $(<250 \mathrm{mesh})$, préconcentrados por elutriação e, em seguida, separados utilizando líquido de alta densidade (bromofórmio) e o separador magnético Frantz. A seleção dos cristais contou com o auxílio de estereomicroscópio e microscópio petrográfico. Para a análise $\mathrm{Pb}-\mathrm{Pb}$ em zircão foi utilizada técnica de filamento duplo proposta por Kober $(1986,1987)$, que utiliza a razão ${ }^{206} \mathrm{~Pb} /{ }^{207} \mathrm{~Pb}$ para determinar a idade aparente de um cristal de zircão. A aquisição de dados foi feita de modo dinâmico utilizando o contador de íons do espectrômetro de massa. A intensidade dos isótopos de $\mathrm{Pb}$ foi medida seguindo a seqüência de massa 204, 206, 207, 208, 206, 207, ao longo de cinco varreduras definindo um bloco de dados com 9 razões ${ }^{207} \mathrm{~Pb} /{ }^{206} \mathrm{~Pb}$. A razão ${ }^{207} \mathrm{~Pb} /{ }^{206} \mathrm{~Pb}$ foi medida em três etapas de evaporação nas temperaturas de 1450 , 1500 e $1550{ }^{\circ} \mathrm{C}$. A média da razão ${ }^{207} \mathrm{~Pb} /{ }^{206} \mathrm{~Pb}$ de cada etapa de evaporação foi determinada com base em 5 blocos de dados, ou até que a intensidade do sinal do sinal de $\mathrm{Pb}$ fosse suficiente para análise. Geralmente, a média da razão ${ }^{207} \mathrm{~Pb} /{ }^{206} \mathrm{~Pb}$ obtida na temperatura mais alta de evaporação foi considerada para o cálculo da idade. Os erros analíticos das idades são apresentados em 2 o. Correção de $\mathrm{Pb}$ comum, para os blocos com razão ${ }^{206} \mathrm{~Pb} /{ }^{204} \mathrm{~Pb}$ maior que 2500 , foi realizada utilizando o modelo de evolução do Pb na Terra em estágio duplo de Stacey \& Kramers (1975).

As análises $\mathrm{Sm}-\mathrm{Nd}$ (idade modelo $\mathrm{T}_{\mathrm{DM}}$ ) foram determinadas em aproximadamente $150 \mathrm{mg}$ de amostra pulverizada, misturada com traçador ${ }^{149} \mathrm{Sm}^{-150} \mathrm{Nd}$. A abertura da amostra foi feita com $\mathrm{HNO}_{3}$ - $\mathrm{HF}$ em bombas Parr, levadas à estufa com temperaturas de $150{ }^{\circ} \mathrm{C}$, por 7 dias. Após evaporação em chapa aquecedora a 100 ${ }^{\circ} \mathrm{C}$ foi novamente adicionado $\mathrm{HNO}_{3}-\mathrm{HF}$ e evaporado. Em seguida, mais duas etapas de evaporação foram realizadas com $\mathrm{HCl}(6.2 \mathrm{~N})$ e $\mathrm{HCl}(2 \mathrm{~N})$. A separação de $\mathrm{Sm}$ e Nd foi realizada por cromatografia de troca iônica em duas etapas. Inicialmente, foi empregada a resina 
Dowex AG 1 x 8 (200-400 mesh), condicionada com $\mathrm{HCl}(2 \mathrm{~N})$ para separar os elementos terras raras, que foram eluídos com $\mathrm{HNO}_{3}(3 \mathrm{~N})$. Posteriormente, utilizando resina Dowex AG 1 x 4 (200-400 mesh) o Sm e o $\mathrm{Nd}$ foram coletados com $\mathrm{HNO}_{3}(7 \mathrm{~N})-$ Metanol. O concentrado final foi depositado em filamento duplo de Ta e Re para análise isotópica. Durante o transcurso das análises, o padrão de Nd "La Jolla" forneceu em média uma razão ${ }^{143} \mathrm{Nd} /{ }^{144} \mathrm{Nd}$ de $0,511854 \pm 0,000010(2 \sigma$ em 3 análises) e o branco total para $\mathrm{Nd}$ ou $\mathrm{Sm}$ foram menores que $170 \mathrm{pg}$. As razões ${ }^{143} \mathrm{Nd} /{ }^{144} \mathrm{Nd}$ foram normalizadas para ${ }^{146} \mathrm{Nd} /{ }^{144} \mathrm{Nd}=0,7219$.

\section{GEOLOGIA E PETROGRAFIA}

Granito do Carmo O Granito do Carmo, conforme definido por Palermo (1988), é representado por um corpo principal maior, com dimensões de $15 \times 5 \mathrm{~km}$ e outras duas exposições ocorrem a sudoeste do corpo principal, em janelas erosivas em meio a coberturas recentes (Fig. 1). Sobre ele se assentam discordantemente os quartzitos do Grupo Natividade e seqüências de rochas sedimentares da Formação Pimenteiras. Para leste, o Granito do Carmo desaparece sob a Bacia do Parnaíba e, portanto, trata-se de um corpo de dimensões bem maiores do que o aflorante. Ao norte, faz contato com rochas vulcânicas félsicas da Formação Monte do Carmo, onde Palermo (1988) relata a presença de enclaves de rochas vulcânicas, sugerindo posicionamento estratigráfico mais novo deste granito. A sudeste faz contato tectônico com o Grupo Natividade através de falhas normais. Por todo o flanco oeste o corpo esconde-se sob coberturas recentes. O plúton aflora nas encostas desnudas da Serra do Carmo, em morrotes, como amontoados de blocos isolados e em lajedos aplainados. Petrograficamente são rochas de granulação grossa, equigranulares, de coloração rósea, predominantemente, variando para cinza-esbranquiçada, leucocráticas ( $\mathrm{M}=5 \mathrm{a}$ 15) com variações holo-leucocráticas que podem ser classificados como biotita-hornblenda sienogranitos e hornblenda monzogranitos (Fig. 2). Texturalmente predomina a textura granular hipidiomórfica apresentando, entretanto, variações locais para tipos porfiríticos. Destaca-se, nesse caso, fenocristais de álcalifeldspatos (até $1,5 \mathrm{~cm}$ ), em matriz de granulação média, inclusive a textura rapakivi. Os minerais essenciais são representados por microclina micropertítica (28-35\%), quartzo (25-40\%), plagioclásio (<15\%), biotita e Fehastingsita (15\% a traços). Os minerais acessórios são representados por apatita, titanita, zircão, alanita e minerais opacos, com traços de cassiterita e fluorita (Palermo 1988). O Granito do Carmo apresenta, em certos locais, zonas miloníticas e cataclásticas, com veios de quartzo auríferos de variadas dimensões. Nos domínios mais deformados os granitos encontram-se fortemente cataclasados e há intensa substituição dos minerais, transformando-os em tipos esverdeados e rosados. Nesse caso, a paragênese original está extensivamente substituída por epídoto, sericita, clorita, carbonato e estilpnomelana, acompanhados de grande remobilização de sílica com mineralizações de ouro, tal como observado por Palermo (1988). Nos domínios deformados o quartzo apresenta

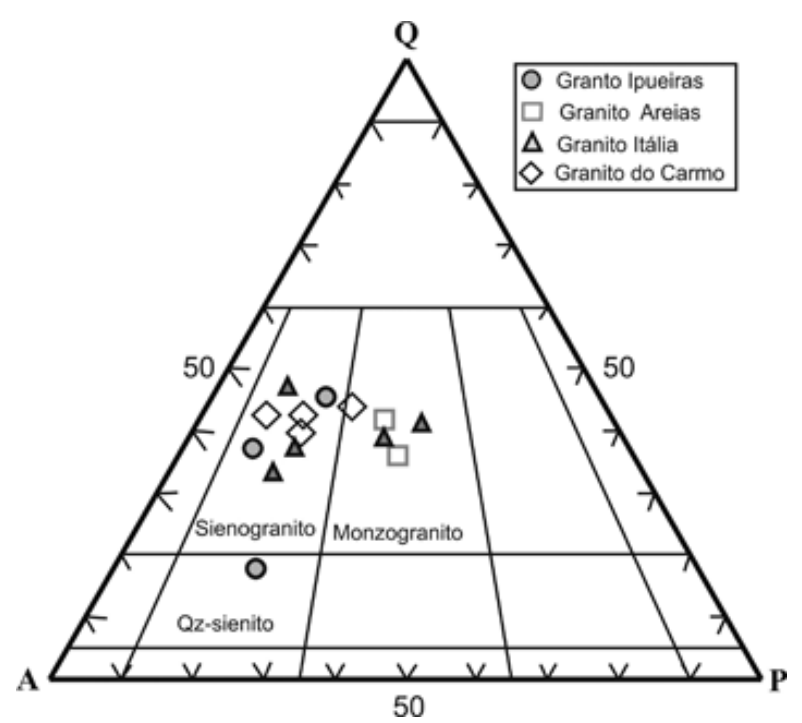

Figura 2 - Diagrama de Streckeisen (1976) mostrando a classificação modal dos granitos estudados.

tons acinzentados ou levemente azulados. Leucogranitos ocorrem mais raramente, sendo tipos de granulação média, cinza rosados, assim como diques e veios de aplitos seccionando as variedades graníticas. Enclaves, parcial ou fortemente transformados, são raros e apresentam granulação fina e composição predominantemente quartzo diorítica, granodiorítica e diorítica.

Granito Areias Este plúton está localizado a sudeste da cidade de Porto Nacional tendo aproximadamente $18 \mathrm{~km}$ de extensão por $3 \mathrm{~km}$ de largura, com maior comprimento na direção N-S (Fig. 1). Suas relações de contato se dão por meio de falhas normais com rochas da Formação Morro do Aquiles e do Grupo Natividade. Petrograficamente são classificados como biotita monzogranitos (Fig. 2) leucocráticos $(\mathrm{M} \sim 9)$, de cor cinza claro, granulação grossa, entretanto processos de cominuição devido ao cisalhamento reduziram a granulação para média a fina (Fig. 3A). Apresentam normalmente textura granular hipidiomórfica, entretanto, nas zonas afetadas por cisalhamento as texturas milonítica são comuns (Fig. 3B). Sua constituição mineralógica essencial inclui quartzo, álcali-feldspato, plagioclásio $\left(\mathrm{An}_{28-31}\right)$ e biotita, tendo como minerais acessórios apatita, alanita, titanita, zircão e minerais opacos. Ao longo do plúton ocorrem porções deformadas com maior ou menor intensidade identificando-se nelas duas fases deformacionais: a primeira é definida pela presença de bandas de cisalhamento frágil-dúcteis que transformaram o granito em protomilonitos e milonitos (Fig. 3A), ao longo das quais estabilizaram a associação clorita, carbonato, sericita e epídoto, acompanhadas de cominuição e recristalização de quartzo e feldspatos; a outra está relacionada à tectônica rúptil bem definida na região, cuja expressão no terreno são falhas normais que definem conjuntos de zonas cataclásticas com espaçamentos centimétricos entre si. Ao longo dessas superfícies de movimentação estão presentes material afaní- 

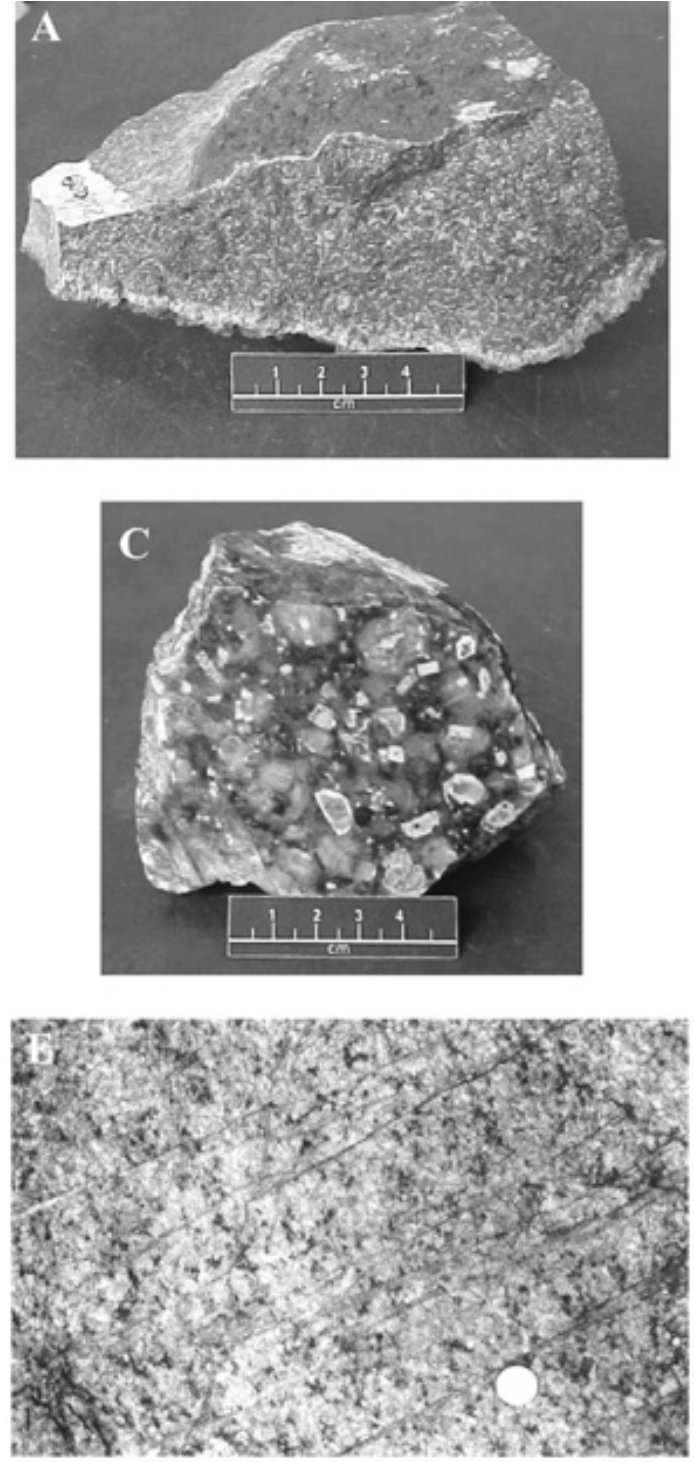
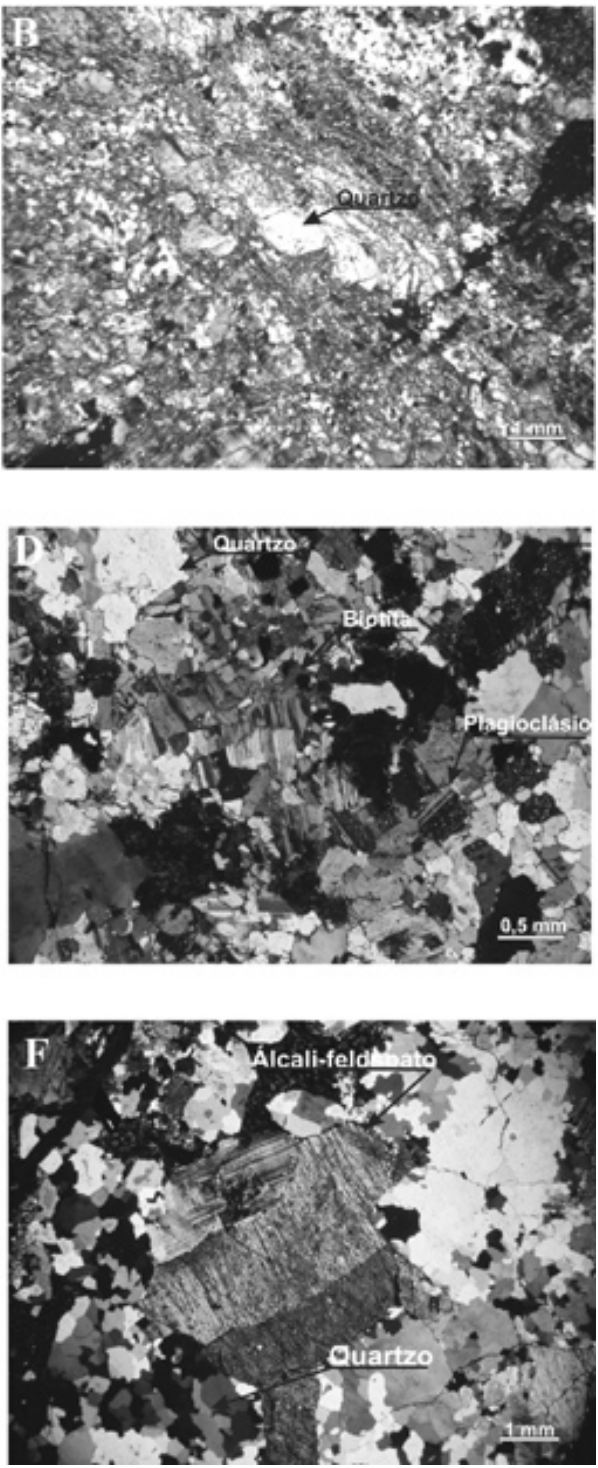

Figura 3 - Características petrográficas dos granitos estudados. Granito Areias: A) Microgranito cominuido em zona de cisalhamento e B) Granito milonitizado com bandas foliadas alternadas com bandas de agregados de quartzo em contato poligonal. Granito Ipueiras: C) Textura rapakivi na borda do granito e D) Textura granular hipidiomórfica. Granito Itália: E) Microzonas de cisalhamento e F) Maclamento em fenocristal de álcalifeldspato pertítico e recristalização de quartzo.

tico verde-escuro com superfícies espelhadas e estrias de falha e, nos seus arredores, intensa fragmentação e venulação de sílica.

Granito Ipueiras Este plúton é representado por um corpo de dimensões batolíticas com $25 \mathrm{~km}$ de comprimento por $15 \mathrm{~km}$ de largura, localizado nos arredores da cidade de Ipueiras (Fig. 1). Uma parte do corpo é capeada por depósitos quaternários no lado oeste, entretanto, contatos por falha são observados com a Formação Morro do Aquiles. No flanco sudeste as relações de contato feita com quartzitos do Grupo Natividade indicam que estes se assentam em discordância erosiva sobre o granito, igualmente ao registrado no Granito do Carmo. Os litotipos predominantes são hornblenda-biotita sienogranitos e hornblenda-biotita-quartzo sienitos (Fig. 2).
São rochas faneríticas de granulação grossa ou média, leucocráticas $(\mathrm{M} \sim 5)$ de coloração cinza claro com tons azulados que estão relacionados à presença de cristais de quartzo azul. Os constituintes mineralógicos essenciais são quartzo, microclina pertítica, plagioclásio $\left(\mathrm{An}_{32-36}\right)$, biotita e hornblenda e os acessórios são titanita, alanita, zircão, apatita e minerais opacos. A textura predominante é granular hipidiomórfica (Fig. 3D), mas na fácies de borda do corpo são registradas texturas porfiríticas, inclusive textura rapakivi (Fig. 3C). Enclaves de rochas máficas com formas ovaladas ou circulares, de dimensões centimétricas, são indicativos de relações intrusivas com rochas da Formação Morro do Aquiles. Em zonas deformadas foram registradas a presença de estilpnomelana e clorita substituindo cristais de biotita ou anfibólio, bem como clorita e carbonato em vênulas associadas a 
essas zonas, o que revela efeitos metamórficos de grau baixo afetando esses granitos. Ao longo dessas zonas que têm orientação preferencial N-S e NE-SW as tramas magmáticas foram parcialmente modificadas com cominuição e imbricamento de minerais. Não foram encontradas rochas vulcânicas félsicas associadas a esse granito conforme relataram Cunha et al. (1981), no entanto, em certos locais foram registradas rochas miloníticas rosadas com granulação muito fina (afaníticas) que podem ser confundidas com tipos vulcânicos.

Granito Itália Constitui um plúton subcircular com diâmetro aproximado de $12 \mathrm{~km}$, localizado a sudoeste da cidade de Ipueiras. Este corpo faz contato direto com o Grupo Natividade no seu flanco sudoeste, sem que se tenha registrado qualquer relação intrusiva. Isso faz supor que os quartzitos estejam assentados discordantemente sobre o granito, conforme registrado nos granitos do Carmo e Ipueiras. No restante o corpo está coberto por sedimentos recentes da planície de inundação do rio Tocantins. Petrograficamente é representado principalmente por biotita-sienogranitos e biotita monzogranitos (Fig. 2) leucocráticos, com índice de cor aproximadamente 5 , de coloração cinza a rosa claro, constituído predominantemente por quartzo, microclina pertítica, plagioclásio $\left(\mathrm{An}_{28-32}\right)$ e biotita, e pelos acessórios alanita, zircão, apatita e minerais opacos. Os aspectos texturais deste granito são semelhantes aos dos demais granitos descritos acima sendo a textura predominante granular hipidiomórfica, destacando-se fácies porfiríticas e variações para textura rapakivi. Também em zonas de deformação os processos de cisalhamento frágil-dúcteis (Fig. $3 E$ ) foram capazes de produzir recristalização dinâmica em quartzo e feldspatos, em locais de forte cominuição, desenhando textura poligonal (Fig. 3F), bem como causando remobilização de sílica e neoformação de sericita, epídoto e clorita que preenchem zonas de movimentação de alto ângulo e vênulas associadas.

LITOGEOQUíMICA Os resultados analíticos dos granitos Areias, Ipueiras, Itália e do Carmo são apresentados na tabela 1. Em seus elementos maiores esses granitos apresentam percentuais elevados de sílica, com valores entre aproximadamente 70 e $79 \%$ e álcalis com valores em torno de $8 \%\left(\mathrm{~K}_{2} \mathrm{O}+\mathrm{Na}_{2} \mathrm{O} \sim 7\right.$ a $9 \%$ ). Os teores de alumina e ferro total são relativamente baixos com variação de 11 a $13 \%$ e 1 a $5 \%$, respectivamente. Para os demais óxidos os teores são muito baixos $\left(\mathrm{CaO}<1,8 ; \mathrm{MgO}<0,43 ; \mathrm{TiO}_{2}<0,43\right.$; $\left.\mathrm{MnO}<0,1 ; \mathrm{P}_{2} \mathrm{O}_{5}<0,1\right)$. Os teores dos elementos traços apresentam-se elevados em Ba (450-1580 ppm), $\mathrm{Ga}(22-29 \mathrm{ppm})$ e nos elementos terras raras ( $\Sigma$ ETR =94-360 ppm). As características geoquímicas revelam serem rochas graníticas de natureza subalcalina, cujo caráter peraluminoso é destacado no diagrama de Maniar \& Picoli (1989), tendo as razões A/CNK superiores a 1 , o que é reforçado pela presença de coríndon normativo em quase todas as amostras $(<2 \%)$, exceto duas amostras que apresentam caráter levemente metaluminoso (Fig. 4). No diagrama de multielementos as rochas dos quatro corpos graníticos revelam grande semelhança composicional entre si, com assinaturas geoquímicas similares, sugerindo afinidade genética entre os plutons estudados (Fig. 5).

Os padrões de elementos terras raras (ETR) apresentam, no geral, grande semelhança entre os plutons, sendo enriquecidos em ETR leves em relação aos pesados, destacando fracionamento moderado a alto em que as razões $(\mathrm{La} / \mathrm{Lu})_{\mathrm{N}}$ variam entre 12 e 86 , com padrões de ETR pesados subhorizontais e anomalias negativas moderadas de európio $\left(\mathrm{Eu} / \mathrm{Eu}^{*}=0,32\right.$ a 1,04), (Fig. 6).

Usando o diagrama $\mathbf{R b}$ versus $\mathbf{Y}+\mathbf{N b}$ de Pearce et al. (1984), para discriminação de ambiência tectônica de granitos, revela que as amostras são distribuídas predominantemente no campo de granitos intraplaca (Fig. 7A), enquanto que no diagrama $\mathbf{Z r}$ versus $\mathbf{1 0 . 0 0 0 * G a / ~}$ Al de Whalen et al. (1987), usado para discriminação geoquímica de granitos as amostras plotam claramente no campo de granitos tipo A (Fig. 7B).

As características geoquímicas como o alto conteúdo de sílica, álcalis e gálio, alta razão $\mathrm{Ga} / \mathrm{Al}$, caráter peraluminoso e padrões de ETR são comparáveis aos granitos tipo A reportados por Whalen et al. (1987) e Eby $(1992,2006)$.

\section{GEOCRONOLOGIA E GEOLOGIA ISOTÓPICA}

Pb-Pb em Zircão Zircões dos granitos Areias, Ipueiras e Itália foram datados pelo método de evaporação de $\mathrm{Pb}$ em monocristais de zircão, os resultados analíticos encontram-se na tabela 2 e as características dos zircões analisados são mostrados na figura 8. O Granito do Carmo já tinha sido datado por Sachett (1996), por meio do método de $\mathrm{Pb}-\mathrm{Pb}$ em zircão, utilizando a técnica do filamento simples, e obteve idade de 2025 $\pm 26 \mathrm{Ma}$. Para o Granito Areias foram analisados sete cristais de zircão que forneceram idades aparentes ${ }^{207} \mathrm{~Pb} /{ }^{206} \mathrm{~Pb}$ entre $2083 \pm 3 \mathrm{Ma}$ e $2107 \pm 6 \mathrm{Ma}$. Uma idade média de $2086 \pm 5$ Ma foi calculada para estes cristais. Do Granito Ipueiras foram datados cinco cristais de zircão, que forneceram idades ${ }^{207} \mathrm{~Pb} /{ }^{206} \mathrm{~Pb}$ entre

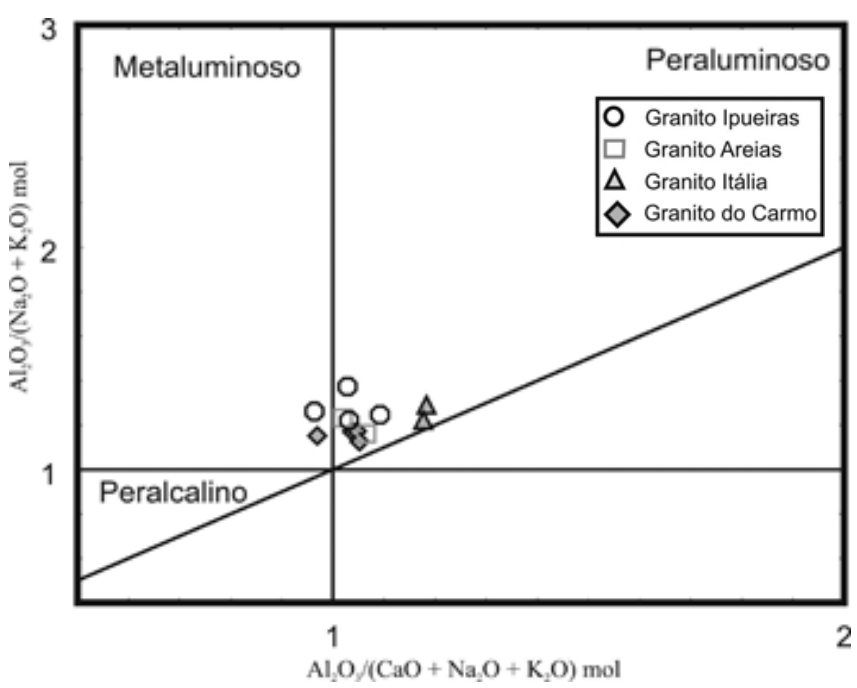

Figura 4 - Diagrama de Maniar \& Piccoli (1989) para classificação geoquímica dos granitos estudados. 
Tabela 1 - Composição química dos granitos paleoproterozóicos da região de Porto Nacional (elementos maiores em \% em peso, traços em ppm).

\begin{tabular}{|c|c|c|c|c|c|c|c|c|c|}
\hline & \multicolumn{4}{|c|}{ GRANITO IPUEIRAS } & \multicolumn{2}{|c|}{ GRANITO AREIAS } & \multicolumn{2}{|c|}{ GRANITO ITÁLIA } & $\begin{array}{c}\text { GRANITO DO } \\
\text { CARMO }\end{array}$ \\
\hline & 99/PN-2 & 99/PN-3 & 01/CL-13 & 01/CL-14a & 99/PN-4 & 01/CL-12 & 01/CL-4b & 01/CL-8 & 01/CL-15 \\
\hline $\mathrm{SiO}_{2}$ & 70,20 & 71,60 & 75,90 & 73,60 & 73,80 & 77,00 & 75,50 & 79,40 & 72,50 \\
\hline $\mathrm{TiO}_{2}$ & 0,40 & 0,43 & 0,17 & 0,22 & 0,15 & 0,07 & 0,17 & 0,10 & 0,23 \\
\hline $\mathrm{Al}_{2} \mathrm{O}_{3}$ & 13,40 & 13,40 & 12,70 & 13,30 & 12,90 & 12,40 & 13,00 & 11,20 & 13,20 \\
\hline $\mathrm{Fe}_{2} \mathrm{O}_{3}$ & 1,10 & 1,43 & 1,20 & 1,04 & 1,20 & 0,21 & 0,80 & 0,95 & 0,80 \\
\hline $\mathrm{FeO}$ & 3,32 & 3,40 & 1,00 & 1,50 & 1,10 & 0,90 & 0,82 & 0,40 & 2,10 \\
\hline $\mathrm{MnO}$ & 0,10 & 0,10 & 0,05 & 0,07 & 0,05 & 0,04 & 0,03 & 0,03 & 0,10 \\
\hline $\mathrm{MgO}$ & 0,34 & 0,43 & 0,17 & 0,24 & 0,21 & 0,20 & 0,25 & 0,14 & 0,20 \\
\hline $\mathrm{CaO}$ & 1,80 & 1,20 & 0,78 & 1,10 & 1,20 & 0,53 & 0,50 & 0,17 & 1,20 \\
\hline $\mathrm{Na}_{2} \mathrm{O}$ & 3,30 & 2,90 & 3,90 & 3,20 & 3,80 & 3,20 & 3,10 & 2,70 & 3,60 \\
\hline $\mathrm{K}_{2} \mathrm{O}$ & 4,80 & 4,60 & 3,50 & 5,20 & 3,90 & 5,00 & 4,60 & 4,40 & 5,10 \\
\hline $\mathrm{P}_{2} \mathrm{O}_{5}$ & 0,10 & 0,10 & 0,01 & 0,05 & 0,04 & 0,01 & 0,01 & 0,04 & 0,04 \\
\hline $\mathrm{PF}$ & 0,30 & 0,26 & 0,10 & 0,23 & 0,70 & 0,20 & 0,53 & 0,22 & 0,37 \\
\hline Total & 99,16 & 99,85 & 99,48 & 99,75 & 99,05 & 99,76 & 99,31 & 99,75 & 99,44 \\
\hline $\mathrm{Ba}$ & 1564 & 1577 & 1063 & 961 & 1038 & 454 & 606 & 310 & 1053 \\
\hline $\mathrm{Rb}$ & 122 & 119 & 44 & 153 & 111 & 116 & 231 & 179 & 212 \\
\hline $\mathrm{Sr}$ & 203 & 217 & 112 & 162 & 192 & 90 & 117 & 42 & 109 \\
\hline $\mathrm{Zr}$ & 484 & 542 & 289 & 342 & 282 & 183 & 229 & 122 & 439 \\
\hline $\mathrm{Nb}$ & 28 & 30 & 9 & 37 & 25 & 12 & 35 & 26 & 28 \\
\hline $\mathrm{Y}$ & 56 & 56 & 18 & 58 & 71 & 45 & 108 & 52 & 45 \\
\hline $\mathrm{Ga}$ & 29 & 26 & 22 & 28 & 28 & 29 & 29 & 26 & 27 \\
\hline Th & 19 & 17 & 5 & 11 & 5 & 5 & 16 & 15 & 15 \\
\hline $\mathrm{Hf}$ & 13 & 13 & 10 & 10 & 10 & 10 & 10 & 10 & 10 \\
\hline $\mathrm{U}$ & 10 & 10 & 10 & 10 & 10 & 10 & 10 & 10 & 10 \\
\hline $\mathrm{La}$ & - & 82,19 & 22,10 & 62,49 & 34,71 & 26,84 & 41,44 & 48,47 & 90,70 \\
\hline $\mathrm{Ce}$ & - & 144,40 & 43,39 & 110,40 & 66,64 & 58,56 & 67,39 & 97,51 & 181,60 \\
\hline $\mathrm{Nd}$ & - & 50,04 & 18,53 & 34,56 & 27,27 & 22,24 & 28,74 & 34,27 & 63,75 \\
\hline $\mathrm{Sm}$ & - & 9,41 & 7,76 & 6,64 & 6,02 & 5,64 & 6,48 & 7,76 & 12,22 \\
\hline $\mathrm{Eu}$ & - & 1,37 & 1,06 & 0,81 & 1,02 & 0,537 & 0,63 & 0,63 & 1,51 \\
\hline $\mathrm{Gd}$ & - & 5,50 & 2,55 & 3,92 & 4,66 & 4,26 & 4,85 & 5,01 & 7,52 \\
\hline Dy & - & 2,63 & 1,41 & 1,81 & 3,78 & 3,04 & 3,04 & 3,35 & 3,58 \\
\hline Ho & - & 0,46 & 0,24 & 0,29 & 0,72 & 0,62 & 0,58 & 0,70 & 0,66 \\
\hline Er & - & 0,98 & 0,61 & 0,71 & 1,79 & 1,67 & 1,58 & 1,92 & 1,56 \\
\hline $\mathrm{Yb}$ & - & 0,70 & 0,41 & 0,47 & 1,43 & 1,40 & 1,16 & 1,75 & 1,14 \\
\hline $\mathrm{Lu}$ & - & 0,10 & 0,07 & 0,07 & 0,19 & 0,22 & 0,71 & 0,27 & 0,18 \\
\hline$\Sigma$ ETR & - & 297,79 & 94,14 & 222,18 & 148,27 & 125,06 & 156,09 & 201,70 & 364,43 \\
\hline $\mathrm{Fe}_{2} \mathrm{O}_{3} / \mathrm{FeO}$ & 0,34 & 0,42 & 1,18 & 0,70 & 1,08 & 0,24 & 0,96 & 2,38 & 0,38 \\
\hline $\mathrm{A} / \mathrm{CNK}$ & 0,96 & 1,03 & 1,09 & 1,03 & 1,02 & 1,07 & 1,18 & 1,18 & 0,97 \\
\hline $\mathrm{Na}_{2} \mathrm{O}+\mathrm{K}_{2} \mathrm{O}$ & 8,10 & 7,50 & 7,40 & 8,40 & 7,70 & 8,20 & 7,70 & 7,10 & 8,70 \\
\hline $\mathrm{K}{ }_{2} \mathrm{O} / \mathrm{Na}_{2} \mathrm{O}$ & 1,45 & 1,59 & 0,90 & 1,63 & 1,03 & 1,56 & 1,48 & 1,63 & 1,43 \\
\hline $\mathrm{Fe} / \mathrm{Mg}$ & 0,93 & 0,92 & 0,93 & 0,92 & 0,92 & 0,87 & 0,88 & 0,91 & 0,94 \\
\hline $\mathrm{Ga} / \mathrm{Al}$ & 4,09 & 3,67 & 3,27 & 3,98 & 4,10 & 4,42 & 4,22 & 4,39 & 3,87 \\
\hline $\mathrm{Rb} / \mathrm{Sr}$ & 0,60 & 0,55 & 0,39 & 0,94 & 0,58 & 1,29 & 1,97 & 4,26 & 1,10 \\
\hline $\mathrm{Ba} / \mathrm{Sr}$ & 7,70 & 7,27 & 9,49 & 5,93 & 5,41 & 5,04 & 5,18 & 7,38 & 9,66 \\
\hline$(\mathrm{La} / \mathrm{Lu}) \mathrm{N}$ & - & 83,64 & 32,31 & 86,48 & 18,38 & 12,38 & 25,15 & 18,49 & 52,30 \\
\hline$(\mathrm{La} / \mathrm{Sm}) \mathrm{N}$ & - & 5,50 & 3,69 & 5,92 & 3,62 & 2,99 & 4,02 & 3,93 & 4,67 \\
\hline$(\mathrm{Gd} / \mathrm{Yb}) \mathrm{N}$ & - & 6,31 & 5,06 & 6,72 & 2,62 & 2,45 & 3,37 & 2,31 & 5,31 \\
\hline $\mathrm{Eu} / \mathrm{Eu}^{*}$ & - & 0,58 & 1,04 & 0,48 & 0,59 & 0,33 & 0,34 & 0,32 & 0,48 \\
\hline
\end{tabular}

$2071 \pm 3$ Ma e $2080 \pm 6$ Ma. A idade média obtida para este corpo granítico foi de $2073 \pm 2 \mathrm{Ma}$. Por fim, cinco cristais de zircão do Granito Itália foram analisados e as idades aparentes ${ }^{207} \mathrm{~Pb} /{ }^{206} \mathrm{~Pb}$ variam entre $2072 \pm 9$ Ma e $2082 \pm 6 \mathrm{Ma}$. A idade média para essas análises é de $2078 \pm 4$ Ma.

As idades ${ }^{207} \mathrm{~Pb} /{ }^{206} \mathrm{~Pb}$ em zircão são interpretadas como idades mínimas de cristalização (Kober 1986,
1987), no entanto, trabalhos anteriores que compararamnas com as idades $\mathrm{U}-\mathrm{Pb}$ tanto pelo método tradicional quanto pelo SHRIMP (Ansdel \& Kyser 1991, Kröner \& Tegtmeyer 1994, Söderlund 1996) demonstraram que as idades 207/206 por evaporação de chumbo se superpõem dentro dos erros analíticos. Assim essas idades são aqui interpretadas como idades de cristalização ou colocação dos plutons estudados. 


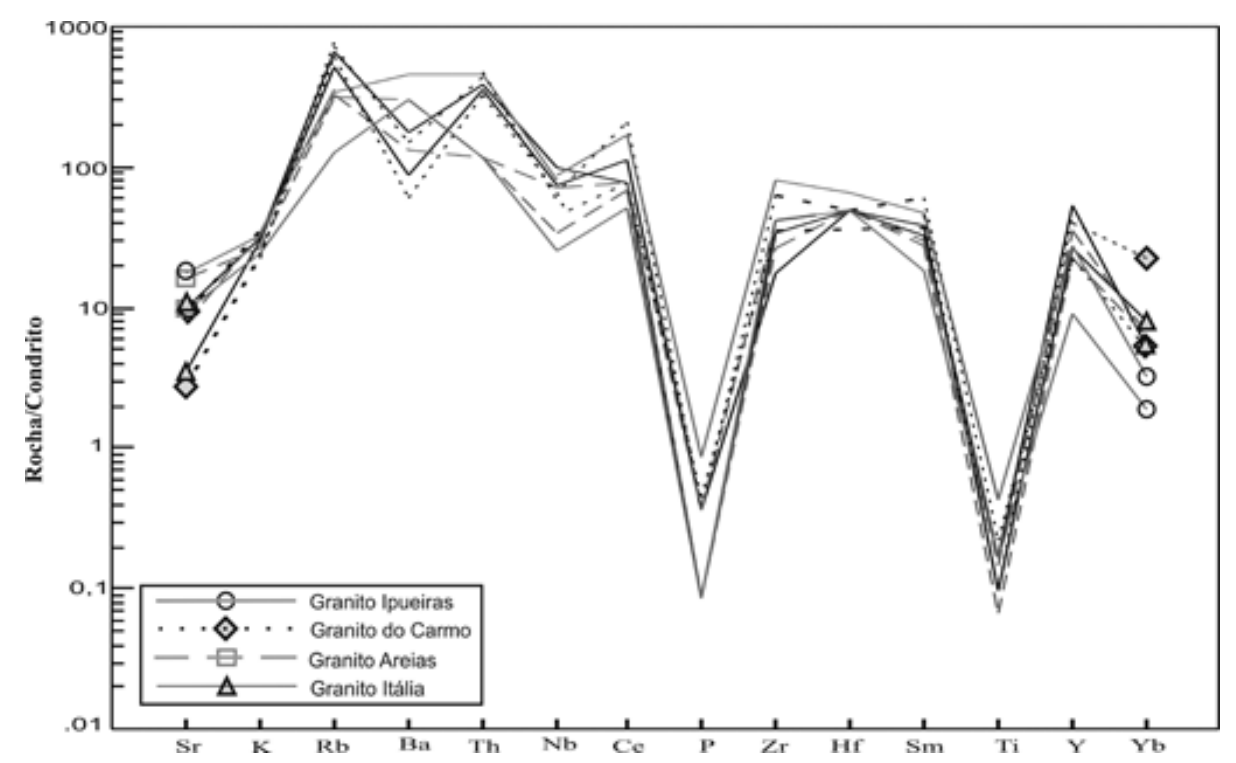

Figura 5 - Diagrama de multi-elementos para os granitos estudados, normalizados pelo condrito de Thompson (1982).

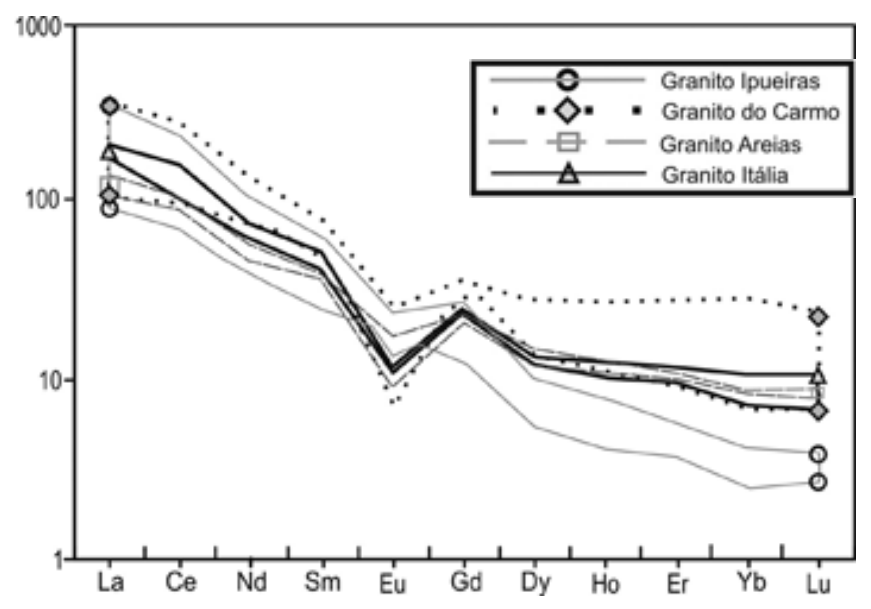

Figura 6 - Diagrama de ETR normalizados para o condrito de Evensen et al. (1978).

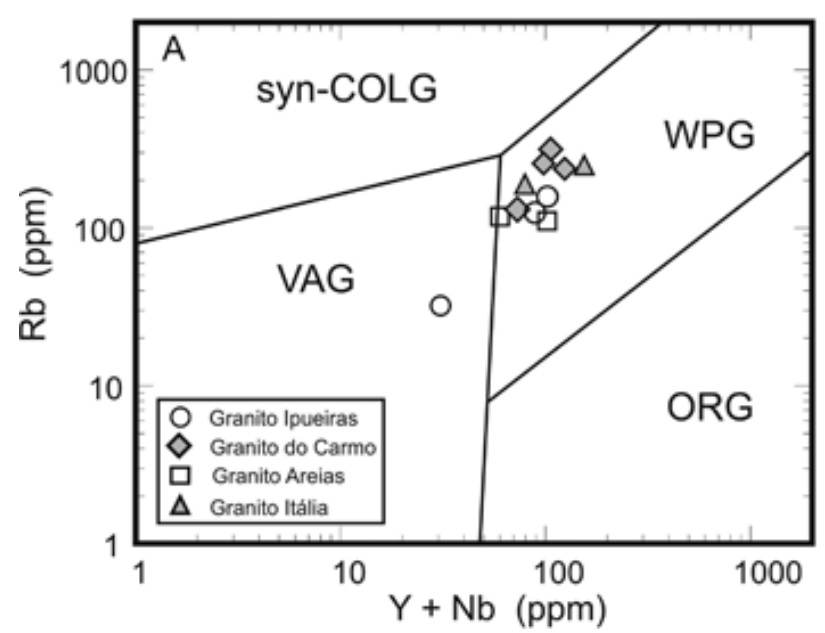

As idades médias obtidas para os três plutons graníticos, conforme se apresentam na tabela 2, são coincidentes e podem ser interpretadas como representativas da época de cristalização e colocação desses corpos graníticos e permitem concluir pela existência de um importante evento de granitogênese de idade paleoproterozóica, em torno de 2,08 Ga, neste domínio do Maciço de Goiás na Província Tocantins. A idade Pb-Pb em zircão de $2025 \pm$ 26 Ma obtida por Sachett (1996) para o Granito do Carmo, considerando o erro analítico, é ligeiramente inferior às idades obtidas nos corpos graníticos ora estudados. Como essa idade foi obtida utilizando a técnica do filamento simples, que pode fornecer idade pouco mais jovem que a idade verdadeira (Gaudette et al. 1998), consideramos que o Granito do Carmo deva ser incluído na Suíte Intrusiva Ipueiras. Essa interpretação é apoiada pelas relações de campo e pelas similaridades petrográfica e litogeoquímica

Figura 7 - Diagramas geoquímicos discriminantes de ambiente tectônico de Pearce et al. (1984), (A); e de tipologia de granitos de Whalen et al. (1987), (B). 
Tabela 2 - Resultados analíticos de evaporação de Pb em zircão para os granitos Areias, Ipueiras e Itália. O erro analítico é calculado em $2 \sigma$.

\begin{tabular}{|c|c|c|c|c|c|c|c|}
\hline \multicolumn{8}{|c|}{ GRANITO AREIAS } \\
\hline Cristal & $\begin{array}{c}\text { Temperatura de } \\
\text { evaporação } \\
\left({ }^{\circ} \mathrm{C}\right)\end{array}$ & $\begin{array}{c}\text { Razões } \\
\text { Utilizadas }\end{array}$ & ${ }^{204} \mathrm{~Pb} /{ }^{206} \mathrm{~Pb}$ & ${ }^{208} \mathrm{~Pb} /{ }^{206} \mathrm{~Pb}$ & $\left({ }^{207} \mathrm{~Pb} /{ }^{206} \mathrm{~Pb}\right) \mathrm{c}$ & Idade (Ma) & $\begin{array}{c}\text { Idade } \\
\text { Média (Ma) }\end{array}$ \\
\hline ARE/01 & 1500 & 14 & $0,000068 \pm 58$ & $0,08443 \pm 164$ & $0,12925 \pm 178$ & $2088 \pm 24$ & $2088 \pm 24$ \\
\hline ARE/04 & 1500 & 32 & $0,000064 \pm 11$ & $0,06487 \pm 43$ & $0,13063 \pm 43$ & $2107 \pm 6$ & $2107 \pm 6$ \\
\hline ARE/06 & $\begin{array}{c}1450 \\
1485 \\
1500^{*} \\
\end{array}$ & $\begin{array}{c}16 \\
34 \\
30 *\end{array}$ & $\begin{array}{c}0,000029 \pm 22 \\
0,000024 \pm 02 \\
0,000324 \pm 324\end{array}$ & $\begin{array}{l}0,10150 \pm 59 \\
0,12432 \pm 32 \\
0,13479 \pm 99\end{array}$ & $\begin{array}{c}0,12906 \pm 115 \\
0,12886 \pm 26 \\
0,12657 \pm 52 \\
\end{array}$ & $\begin{array}{c}2085 \pm 16 \\
2083 \pm 4 \\
2051 \pm 7\end{array}$ & $2083 \pm 3$ \\
\hline ARE/07 & $\begin{array}{c}1450^{*} \\
1500 \\
\end{array}$ & $\begin{array}{l}4^{*} \\
34 \\
\end{array}$ & $\begin{array}{c}0,000829 \pm 716 \\
0,000047 \pm 06\end{array}$ & $\begin{array}{c}0,08497 \pm 346 \\
0,12483 \pm 41 \\
\end{array}$ & $\begin{array}{l}0,12817 \pm 71 \\
0,12890 \pm 19 \\
\end{array}$ & $\begin{array}{c}1997 \pm 14 \\
2083 \pm 3 \\
\end{array}$ & $2083 \pm 3$ \\
\hline ARE/09 & 1500 & 32 & $0,000046 \pm 14$ & $0,11736 \pm 32$ & $0,12896 \pm 28$ & $2084 \pm 4$ & $2084 \pm 4$ \\
\hline $\mathrm{ARE} / 11$ & 1500 & 38 & $0,000029 \pm 05$ & $0,12639 \pm 53$ & $0,12960 \pm 68$ & $2093 \pm 9$ & $2093 \pm 9$ \\
\hline $\mathrm{ARE} / 12$ & $\begin{array}{l}1450 \\
1500 \\
\end{array}$ & $\begin{array}{l}36 \\
30 \\
\end{array}$ & $\begin{array}{l}0,000034 \pm 07 \\
0,000011 \pm 03\end{array}$ & $\begin{array}{l}0,10142 \pm 58 \\
0,12903 \pm 65 \\
\end{array}$ & $\begin{array}{l}0,12864 \pm 27 \\
0,12953 \pm 22 \\
\end{array}$ & $\begin{array}{l}2080 \pm 4 \\
2092 \pm 3 \\
\end{array}$ & $2087 \pm 12$ \\
\hline & & 266 Razões & & & & Idade Média & $2086 \pm 5$ \\
\hline \multicolumn{8}{|c|}{ GRANITO IPUEIRAS } \\
\hline IPU/02 & 1500 & 36 & $0,000064 \pm 04$ & $0,14259 \pm 39$ & $0,12863 \pm 45$ & $2080 \pm 6$ & $2080 \pm 6$ \\
\hline IPU/03 & $\begin{array}{l}1450 * \\
1500\end{array}$ & $\begin{array}{c}34 * \\
24\end{array}$ & $\begin{array}{l}0,000266 \pm 10 \\
0,000136 \pm 09\end{array}$ & $\begin{array}{c}0,12748 \pm 152 \\
0,12366 \pm 42\end{array}$ & $\begin{array}{l}0,12696 \pm 51 \\
0,12812 \pm 34\end{array}$ & $\begin{array}{l}2057 \pm 7 \\
2073 \pm 5\end{array}$ & $2073 \pm 5$ \\
\hline IPU/04 & $\begin{array}{c}1450 * \\
1500 * \\
1550 \\
\end{array}$ & $\begin{array}{c}38^{*} \\
28^{*} \\
36 \\
\end{array}$ & $\begin{array}{l}0,001051 \pm 75 \\
0,000910 \pm 14 \\
0,000147 \pm 04 \\
\end{array}$ & $\begin{array}{l}0,13263 \pm 54 \\
0,13261 \pm 34 \\
0,10557 \pm 28 \\
\end{array}$ & $\begin{array}{l}0,12806 \pm 42 \\
0,12890 \pm 24 \\
0,12803 \pm 23 \\
\end{array}$ & $\begin{array}{l}2072 \pm 6 \\
2083 \pm 3 \\
2071 \pm 3 \\
\end{array}$ & $2071 \pm 3$ \\
\hline IPU/05 & $\begin{array}{c}1450 * \\
1500 \\
1550 \\
\end{array}$ & $\begin{array}{c}22 * \\
34 \\
34 \\
\end{array}$ & $\begin{array}{l}0,001251 \pm 82 \\
0,000075 \pm 04 \\
0,000112 \pm 05 \\
\end{array}$ & $\begin{array}{c}0,14269 \pm 116 \\
0,11612 \pm 27 \\
0,11960 \pm 48 \\
\end{array}$ & $\begin{array}{l}0,12483 \pm 94 \\
0,12810 \pm 34 \\
0,12814 \pm 33 \\
\end{array}$ & $\begin{array}{l}2027 \pm 1 \\
2072 \pm 5 \\
2073 \pm 5 \\
\end{array}$ & $2072 \pm 3$ \\
\hline IPU/06 & 1500 & 32 & $0,000201 \pm 09$ & $0,13637 \pm 111$ & $0,12845 \pm 76$ & $2077 \pm 1$ & $2077 \pm 10$ \\
\hline & & 196 Razões & & & & Idade Média & $2073 \pm 2$ \\
\hline \multicolumn{8}{|c|}{ GRANITO ITÁLIA } \\
\hline ITA/01 & $\begin{array}{l}1450 \\
1500 \\
\end{array}$ & $\begin{array}{l}34 \\
38 \\
\end{array}$ & $\begin{array}{l}0,000047 \pm 02 \\
0,000067 \pm 13\end{array}$ & $\begin{array}{l}0,09943 \pm 35 \\
0,12305 \pm 93\end{array}$ & $\begin{array}{l}0,12792 \pm 47 \\
0,12840 \pm 43\end{array}$ & $\begin{array}{l}2070 \pm 6 \\
2077 \pm 6\end{array}$ & $2074 \pm 7$ \\
\hline ITA/03 & $\begin{array}{c}1450^{*} \\
1500 \\
\end{array}$ & $\begin{array}{l}8^{*} \\
39 \\
\end{array}$ & $\begin{array}{l}0,000000 \pm 00 \\
0,000022 \pm 06\end{array}$ & $\begin{array}{l}0,10172 \pm 49 \\
0,11116 \pm 34\end{array}$ & $\begin{array}{l}0,12690 \pm 44 \\
0,12838 \pm 37\end{array}$ & $\begin{array}{l}2056 \pm 6 \\
2076 \pm 5 \\
\end{array}$ & $2076 \pm 5$ \\
\hline ITA/04 & $\begin{array}{l}1450 \\
1500 \\
1550 \\
\end{array}$ & $\begin{array}{l}36 \\
36 \\
34 \\
\end{array}$ & $\begin{array}{l}0,000056 \pm 16 \\
0,000055 \pm 09 \\
0,000076 \pm 13\end{array}$ & $\begin{array}{c}0,09282 \pm 47 \\
0,12151 \pm 80 \\
0,14759 \pm 125 \\
\end{array}$ & $\begin{array}{l}0,12730 \pm 73 \\
0,12803 \pm 34 \\
0,12898 \pm 67 \\
\end{array}$ & $\begin{array}{c}2061 \pm 10 \\
2071 \pm 5 \\
2084 \pm 9 \\
\end{array}$ & $2072 \pm 9$ \\
\hline ITA/05 & 1500 & 36 & $0,000007 \pm 03$ & $0,13308 \pm 35$ & $0,12878 \pm 20$ & $2082 \pm 3$ & $2082 \pm 3$ \\
\hline \multirow[t]{2}{*}{ ITA/07 } & $\begin{array}{c}1450 * \\
1500 \\
\end{array}$ & $\begin{array}{c}38^{*} \\
36 \\
\end{array}$ & $\begin{array}{l}0,000993 \pm 17 \\
0,000034 \pm 03\end{array}$ & $\begin{array}{c}0,13430 \pm 150 \\
0,11201 \pm 34\end{array}$ & $\begin{array}{l}0,12587 \pm 72 \\
0,12881 \pm 44\end{array}$ & $\begin{array}{l}2041 \pm 1 \\
2082 \pm 6\end{array}$ & $2082 \pm 6$ \\
\hline & & 289 Razões & & & & Idade Média & $2078 \pm 4$ \\
\hline
\end{tabular}

* temperaturas e razões extraídas do cálculo da idade.

do Granito do Carmo com os demais corpos estudados.

As idades $\mathrm{Pb}-\mathrm{Pb}$ em zircão obtidas para os granitos Areias, Ipueiras e Itália, em torno de 2,08 Ga, vem demonstrar que as idades $\mathrm{Rb}-\mathrm{Sr}$ desses granitos da região, publicadas em diversos trabalhos, devem ser interpretadas com cautela, uma vez que não refletem a idade de cristalização desses granitos. Como exemplos, se podem citar as idades convencionais (idade de referência) de $1637 \pm 14$ Ma para corpos a sudeste de Porto Nacional (Hasui et al. 1980 ) e de $2069 \pm 74$ Ma e $1737 \pm 50$ Ma para o Granito
Itália (Cunha et al. 1981); e as idades isocrônicas de 1873 \pm 25 Ma para corpos graníticos entre Porto Nacional e Monte do Carmo (Hasui et al. 1984) e de $1741 \pm 54 \mathrm{Ma}$ para o Granito do Carmo (Barradas et al. 1992).

Idade Modelo Sm-Nd Idades-modelo Sm-Nd em rocha total foram obtidas em duas amostras dos granitos Ipueiras e Areias, e os resultados analíticos estão apresentados na tabela 3 . As idades $\mathrm{T}_{\mathrm{DM}}$ de 2,17 e $2,15 \mathrm{Ga}$ para o Granito Ipueiras e de 2,18 e 2,19 Ga para o Gra- 

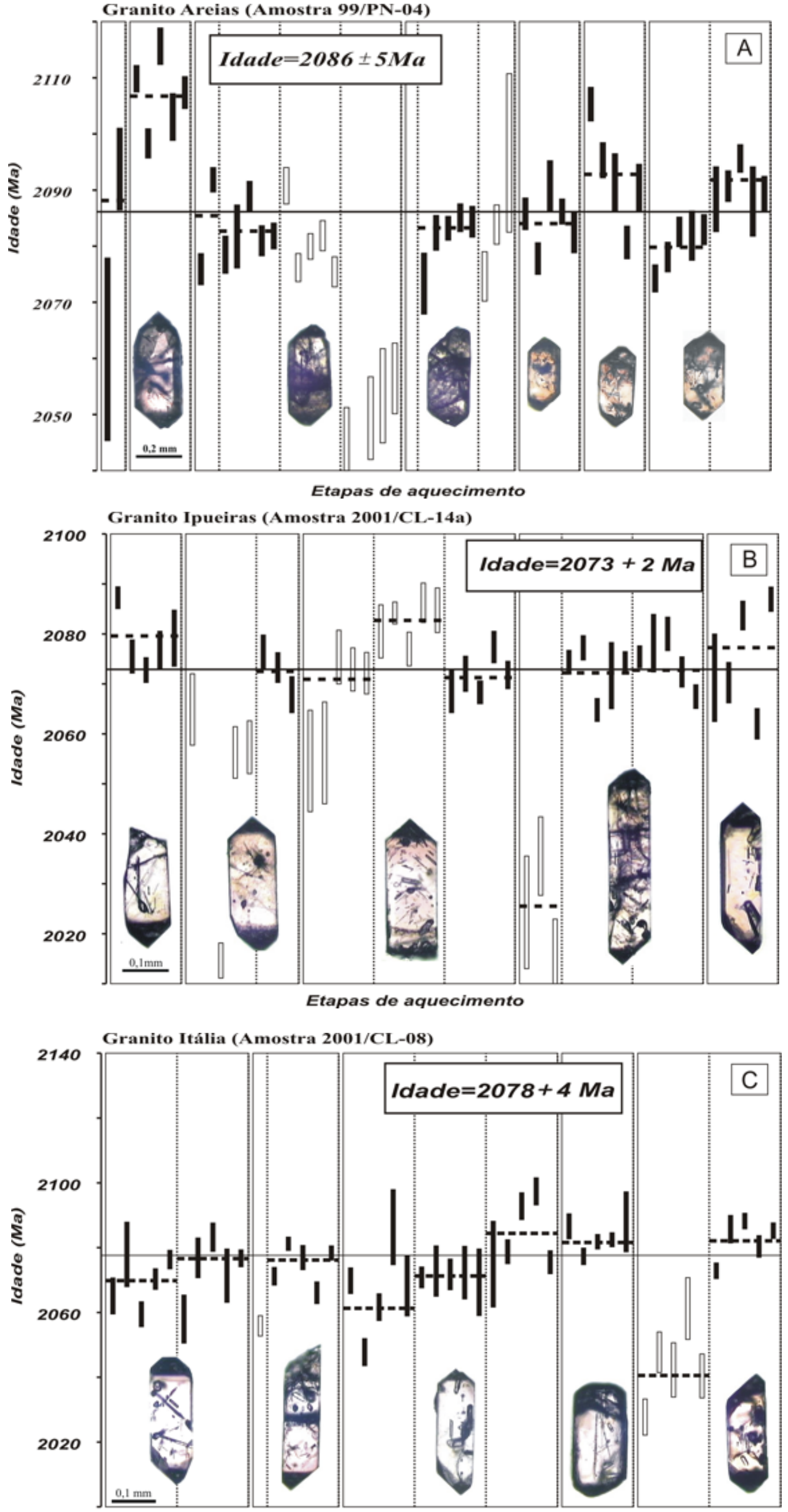

Figura 8 - Diagramas de Idade versus Etapa de Evaporação dos cristais de zircão do Granito Areias (A), Granito Ipueiras (B) e Granito Itália (C). 
Tabela 3 - Dados isotópicos Sm-Nd em rocha total dos granitos Ipueiras e Areias. Idade $T_{D M}(\mathrm{Ga})$ calculada segundo De Paolo (1981).

\begin{tabular}{c|c|c|c|c|c|c|c|c|c|c}
\hline Granito & Amostra & $\mathrm{Sm}$ & $\mathrm{Nd}$ & $\mathrm{Sm} / \mathrm{Nd}$ & $f \mathrm{Sm} / \mathrm{Nd}$ & ${ }^{147} \mathrm{Sm} /{ }^{144} \mathrm{Nd}$ & ${ }^{143} \mathrm{Nd} /{ }^{144} \mathrm{Nd}$ & $\mathrm{E}_{\mathrm{Nd}}(0)$ & $\begin{array}{c}\varepsilon_{\mathrm{Nd}(2.08} \\
(\mathrm{G})\end{array}$ & $\begin{array}{c}\mathrm{T}_{\mathrm{DM}} \\
(\mathrm{Ga})\end{array}$ \\
\hline Ipueiras & $99 / \mathrm{PN}-01$ & 4,20 & 15,56 & 0,270 & $-0,170$ & $0,16330 \pm 8$ & $0,512328 \pm 6$ & $-6,05$ & $+2,89$ & 2,17 \\
\hline Ipueiras & $99 / \mathrm{PN}-02$ & 15,68 & 96,37 & 0,163 & $-0,500$ & $0,09834 \pm 74$ & $0,511418 \pm 12$ & $-23,80$ & $+2,49$ & 2,15 \\
\hline Areias & $99 / \mathrm{PN}-04$ & 7,52 & 37,94 & 0,198 & $-0,391$ & $0,11975 \pm 19$ & $0,511700 \pm 5$ & $-18,30$ & $+2,27$ & 2,18 \\
\hline Areias & $2001 / \mathrm{CL}-12$ & 6,10 & 29,22 & 0,208 & $-0,358$ & $0,12622 \pm 3$ & $0,511788 \pm 2$ & $-16,58$ & $+2,26$ & 2,19 \\
\hline
\end{tabular}

nito Areias, indicam que esses granitóides foram gerados a partir da fusão parcial de uma fonte paleoproterozóica. Os valores de $\varepsilon \mathrm{Nd}_{(2,08 \mathrm{Ga})}$ são positivos, sendo de $+2,49 \mathrm{e}$ $+2,89$ para o Granito Ipueiras e de $+2,27$ e $+2,26$ para o Granito Areias, e sugerem contribuição mantélica para a formação desses corpos. Os valores de $\varepsilon \mathrm{Nd}$, associados à pequena diferença entre a idade de cristalização das rochas $(2,08 \mathrm{Ga})$ e suas idades $\mathrm{T}_{\mathrm{DM}}$, revelam curto tempo de residência crustal para a rocha fonte da qual derivou este magmatismo granítico, caracterizando domínio juvenil, nesta porção do Maciço de Goiás.

As idades modelo $\left(\mathrm{T}_{\mathrm{DM}}\right)$ destes granitos revelam um evento de acresção crustal ao embasamento paleoproterozóico desta porção da Província Tocantins e são coerentes com as idades de Fuck et al. (2002) para o bloco definido na região de Porto Nacional $\left(\mathrm{T}_{\mathrm{DM}}\right.$ de 2,3 a 2,0 Ga) de geração de uma crosta continen- tal juvenil paleoproterozóica, relacionada ao evento Transamazônico. Em princípio, os terrenos gnáissicos e granulíticos reunidos no Complexo Porto Nacional, com idade em torno de $2,15 \mathrm{Ga}$, seriam candidatos naturais como rocha fonte desses corpos graníticos. No entanto, as idades $\mathrm{T}_{\mathrm{DM}}$ entre $2,40 \mathrm{Ga}$ e $2,55 \mathrm{Ga}$ e os valores de $\varepsilon N d_{(2,08 \mathrm{Ga}}$ entre $-2,31$ e $+0,42$ para os granulitos (Gorayeb \& Moura 2002) tornam menos provável esta possibilidade. Uma fonte alternativa para esses granitos seriam os terrenos gnáissicos do Complexo Rio dos Mangues $(2,12 \mathrm{Ga})$, ou seqüências correlatas da região ainda pouco conhecidas. Idades modelo de ortognaisses tonalíticos desse complexo com valores de 2,21 Ga e 2,25 Ga (Arcanjo 2002) e de $\varepsilon N d(2,08$ Ga) de $+1,11$ e $+1,98$ são compatíveis os dados obtidos para os granitos estudados (Fig. 9).

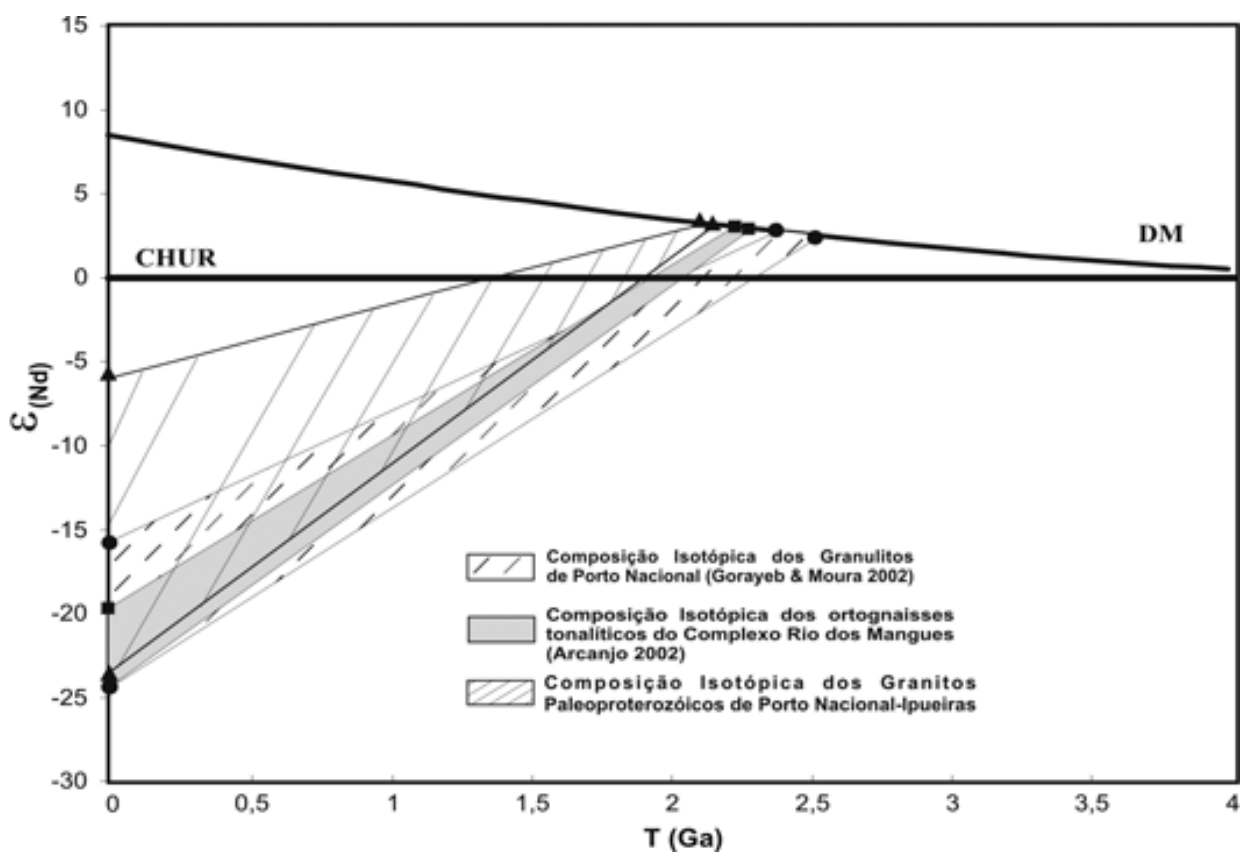

Figura 9 - Diagrama Idade $T_{D M}$ versus $\varepsilon N d$ representando os campos de evolução isotópica dos granulitos e granitos do Paleoproterozóico da região de Porto Nacional e dos ortognaisses tonalíticos do Complexo Rio dos Mangues. 
CONSIDERAÇÕES FINAIS Os dados provenientes dos levantamentos de campo associados aos estudos petrográficos e litogeoquímico revelaram similaridade entre os granitos do Carmo, Areias, Ipueiras e Itália, que são reunidos na Suíte Intrusiva Ipueiras. Tratase de granitos subalcalinos de caráter peraluminoso e geoquímica comparável à dos granitos do tipo A descritos por Whalen et al. (1987). As rochas dos diferentes plútons concentram-se no campo de sienogranito e monzogranito, e apresentam constituição mineralógica similar, tanto das fases principais como das varietais e acessórias. Da mesma forma, as rochas destes corpos possuem aspectos texturais semelhantes. No que diz respeito aos aspectos deformacionais, as estruturas geradas são similares em todos os quatro corpos graníticos bem como as associações minerais neoformadas. As transformações minerais relacionadas à deformação podem estar ligadas aos processos tectonotermais da evolução do Grupo Natividade no Neoproterozóico que atingiram condições metamórficas da fácies xisto-verde baixo associadas a remobilização de fases fluidas (sílica, carbonatos, $\mathrm{H}_{2} \mathrm{O}$, Au e outros componentes) que afetaram parcialmente os corpos. Suas relações de contato sugerem que estes corpos são intrusivos nas rochas das formações Morro do Aquiles e Monte do Carmo do Paleoproterozóico. Em relação ao Grupo Natividade, do Neoproterozóico, os quartzitos estão assentados sobre esses granitos em discordância erosiva. Os estudos geocronológicos revelaram idades em torno de 2,08 Ga para os granitos Areias, Ipueiras e Itália mostrando que são cronocorrelatos. Isto corrobora os dados de campo, petrográficos e litogeoquímicos, que apontam afinidade desses plútons permitindo reuni-los na Suíte Intrusiva Ipueiras, incluindo o Granito do Carmo. Tal fato caracteriza a existência de um importante evento de grani- togênese do Paleoproterozóico no setor setentrional da Província Tocantins. Considerando serem granitos tipo A, de ambiente tectônico intraplaca e que apresentam idade pouco mais jovem que a das rochas ortoderivadas dos complexos Rio dos Mangues e Porto Nacional $(2,12-2,15 \mathrm{Ga})$ se pode interpreta-los como relacionado aos pulsos magmáticos das fases tardias do evento termo tectônico Transamazônico bem caracterizado nesta região. As idades-modelo $\mathrm{Sm}-\mathrm{Nd}$, com valores de $\mathrm{T}_{\mathrm{Dm}}$ entre 2,19 e 2,15 Ga e $\varepsilon N d_{(2,08 \text { Ga })}$ positivos entre $+2,5$ e $+2,9$ mostram pouco tempo de residência crustal dessas rochas, e os valores de $\varepsilon N d$ indicam contribuição mantélica para a formação desses corpos. Esses dados permitem relacionar a formação destes granitos à fusão parcial de um domínio crustal juvenil de idade paleoproterozóica do Maciço de Goiás. Adicionalmente, vem revelar a ausência de crosta arqueana neste domínio do Maciço de Goiás. Tudo isso vem ordenar cronologicamente esses granitos em um intervalo bem definido do Paleoproterozóico e distingui-los de outros eventos de granitogênese conhecidos na região.

Agradecimentos Ao CNPq pelo apoio no financiamento da pesquisa através dos projetos "Magmatismo, evolução crustal e metalogênese da Província Mineral de Carajás e províncias adjacentes" (PRONEX103/98-MCT/CNPq) e "Magmatismo da Província Amazônia Central e Mineralizações Associadas" (400038/99 - CNPq/PNOPG). A CAPES pelo suporte financeiro da bolsa de mestrado do primeiro autor. Ao Programa de Pós-Graduação em Geologia e Geoquímica/Instituto de Geociências/UFPA pelo apoio material e administrativo para o desenvolvimento da pesquisa. Os autores agradecem aos revisores pelas criticas e sugestões.

\section{Referências}

Ansdel K.M. \& Kyser T.K. 1991. Plutonism, deformation, and metamorphism in the proterozoic Flin Flon reenstone belt, Canada: limits on timing provided by the singlezircon Pb-evaporation technique. Geology, 19:518-521.

Arcanjo S.H.S. 2002. Evolução geológica das seqüencias do embasamento na porção sul do Cinturão AraguaiaRegião de Paraíso do Tocantins. Tese de Doutoramento, Universidade Federal do Pará, 176p.

Arcanjo S.H.S. \& Moura C.A.V. 2000. Geocronologia das rochas do embasamento do setor meridional do Cinturão Araguaia na região de Paraíso do Tocantins (TO). Rev. Bras. Geoc., 30:665-670.

Barbosa O., Andrade Ramos J.R., Gomes F.A., Hembold D.R. 1966. Geologia estratigráfica, estrutural e econômica da área do Projeto Araguaia. Monografia da Divisão de Geologia e Mineralogia/DNPM, RJ, nº19, 95p.

Barradas J.A.S., Lafon J.M., Kotschoubey B. 1992. Geocronologia $\mathrm{Pb}-\mathrm{Pb}$ e $\mathrm{Rb}-\mathrm{Sr}$ da região de Monte do CarmoPorto Nacional, TO. Novos resultados. In: Congr. Bras. Geol., 37, São Paulo. Bol. Res. Exp., v. 2, p. 241-264.

Chaves C.L. 2003. Caracterização geológica, petrográfica, geoquímica e geocronológica do magmatismo granítico da Região de Porto Nacional-TO. Dissertação de Mestrado, Universidade Federal do Pará, 150p.

Costa J.B.S. 1985. Aspectos lito-estruturais e evolução crustal da região centro-norte de Goiás. Tese de Doutoramento, Universidade Federal do Pará, 209p.

Costa J.B.S., Lemos R.L., Martins J.P.A., Beltrão L.F., Góes A.M., Hasui Y. 1984. Geologia da região de Porto Nacional. Rev. Bras. Geoc., 14:3-11.

Cunha B.C., Potiguar L.A.T., Ianhez A.C., Bezerra P.E.L., Pitthan J.M.L., Souza Jr. J.J., Montalvão R.M.G., Souza A.M.S., Hildred T.R., Tassinari C.C.C. 1981. Projeto RADAMBRASIL, Folha SC.22-Tocantins, Geologia, 1:21-196.

DePaolo D.J. 1981. Neodymium isotopes in the Colorado Front Range and crust-mantle evolution in the Proterozoic. Nature, 291:193-197.

Eby G.N. 1992. Chemical subdivision on the A-type granitoids: petrogenetic and tectonic implication. Geology, 20:641-644.

Eby G.N. 2006. Distributions between A-type granites and 
petrogenetic pathways. In: Symposium on magmatism, metalogenesis, and crustal evolution of the Amazonian Craton, Belém, PRONEX-UFPA/SBG-NO, Abstracts and Field Trips, p.15.

Evensen N.M., Hamilton P.J., O’Nions R.K. 1978. Rare earth abundance in chondritic meteorites. Geochimica Cosmochimica, 42:1199-1212.

Fuck R.A., Dantas E.L., Pimentel M.M., Botelho N.F., Junges S.L., Holanda M.H.B.M., Moraes R., Armstrong R. 2002. Crosta continental Paleoproterozóica no embasamento da porção norte da Faixa Brasília: Novos dados Sm-Nd e U-Pb. In: SBG, Congr. Bras. Geol., 41, João Pessoa, Anais, p.308.

Gaudette H. E., Lafon J.M., Macambira M.J.B., Moura C.A.V., Scheller T. 1998. Comparison of single filament $\mathrm{Pb}$ evaporation/ionization zircon ages with conventional $\mathrm{U}-\mathrm{Pb}$ results: examples from Precambrian of Brazil. $J$. South Americ. Earth Sci., 11:351-363.

Gorayeb P.S.S. \& Moura C.A.V. 2001. Aspectos geológicos e geocronológicos do Anortosito Carreira Comprida, região de Porto Nacional-TO. In: Simp. Geol. Amaz., 7, Belém, Bol. Res. Exp., SBG-NO, CD Rom.

Gorayeb P.S.S. \& Moura C.A.V. 2002. Idades modelo $\mathrm{T}_{\mathrm{DM}}$ dos granulitos de Porto Nacional-TO. In: SBG, Congr. Bras. Geol., 41, João Pessoa, Anais, p.30.

Gorayeb P.S.S. \& Moura C.A.V. 2006. Granitogenesis events in the northern portion of the Tocantins Province, Brazil. In: Symposium on magmatism, metalogenesis, and crustal evolution of the Amazonian Craton, Belém, PRONEX-UFPA/SBG-NO, Abstracts and Field Trips,p.21.

Gorayeb P.S.S. \& Moura C.A.V. 2008. Investigation of magmatic events in the Tocantins Province - Northern Brazil using Sm-Nd TDM ages and Pb-evaporation zircon ages of granitic rocks. In: South American Symposium on Isotope Geology, 6, San Carlos de Bariloche, Book of Abstracts, p.161.

Gorayeb P.S.S., Moura C.A.V., Arcanjo S.H.S. 2000a. Granitogenesis events in the Porto Nacional-Palmas-Paraiso do Tocantins region, Tocantins Province, Brazil. In: Intern. Geol. Cong., 31, RJ., SBG, Anais, CD-Rom.

Gorayeb P.S.S., Moura C.A.V., Barros G.R. 2000b. Pb-Pb zircon ages of the Porto Nacional high-grade metamorphic terrain, northern portion of the Goiás Massif, Central Brazil. Rev. Bras. Geoc., 30:190-194.

Gorayeb P.S.S., Moura C.A.V., Chaves C.L. 2001. A granitogênese neoproterozóica no setor setentrional da Província Tocantins: implicações para redefinição da Suíte Lajeado. In: SBG-NO, Simp. Geol. Amaz., 7, Belém, Boletim de Resumos Expandidos, CD-Rom.

Gorayeb P.S.S. 1996. Petrologia e evolução crustal das rochas de alto grau de Porto Nacional-TO. Tese de Doutorado, Universidade Federal do Pará, 262 p.

Gorayeb P.S.S., Palermo N., Leite A.A.A. 1992. As vulcânicas de Monte do Carmo-TO: caracterização geológicapetrográfica e relacionamento estratigráfico com o Grupo Natividade, Granito do Carmo e Formação Monte do Carmo. In: SBG, Congr. Bras. Geol. 37, São Paulo, Bol. Res. Expand., p. 313-314.

Hasui Y. \& Costa J.B.S. 1990. O Cinturão Araguaia: um novo enfoque estrutural-estratigráfico. In: SBG, Congr. Bras.
Geol., 36, Natal, Anais, 5:2535-2549.

Hasui Y., Costa J.B.S., Gorayeb P.S.S., Lemos R.L., Gama Jr. T., Bemerguy R.L. 1984. Geologia da região de Paraíso do Norte de Goiás. In: SBG, Cong. Bras. Geol., 33 , RJ, Anais, p. 2220-2230.

Hasui Y., Tassinari C.C.C., Siga Jr O., Teixeira E., Kawashita K., Almeida F.F.M. 1980. Datações Rb/Sr e K/Ar do centro-norte do Brasil e seu significado geotectônico. In: Congr. Bras. Geol. 31, Camboriú, SBG, Anais, 5:25692576.

Kober B. 1986. Whole grain evaporation for $207 \mathrm{~Pb} / 206 \mathrm{~Pb}$ age investigations on single zircons using a double filament source. Contrib. Mineral. Petrol., 93:482-490.

Kober B. 1987. Single grain evaporation combined with $\mathrm{Pb}+$ emitter bedding for $207 \mathrm{~Pb} / 206 \mathrm{~Pb}$ investigations using thermal ion mass spectrometry, and implications for zirconology. Contrib. Mineral. Petrol., 96:63-71.

Kröner A. \& Tegtmeyer A. 1994. Gneiss-greenstone relationships in the Ancient Gneiss Complex of southwestern Swaziland, southern Africa, and implications for early crustal evolution: Precamb. Res., 67:109-139.

Maniar P.D. \& Piccoli P.M. 1989. Tectonic discrimination of granitoids. Geol. Soc. of America Bulletin, 101:635643.

Moura C.A.V. \& Sousa C.S. 2002. Idades Pb-Pb em zircão do Granito Santa Luzia: implicações para a determinação da idade da granitogênese brasiliana tardi-tectônica no Cinturão Araguaia (TO). In: SBG, Congr. Bras. Geol., 41, João Pessoa. Anais, p.500.

Palermo N.1988. Geologia e mineralizações auríferas da região de Monte do Carmo, Goiás. Dissertação de Mestrado, Univ. Federal do Rio de Janeiro. RJ, 139p.

Pearce J.A., Harris N.B.W., Tindle A.G. 1984. Trace element discrimination diagrams for the tectonic interpretation of granitic rocks. J. Petrol., 4:956-983.

Sachett C.R. 1996. Geologia, geoquímica isotópica e aspectos metalogenéticos das rochas ígneas e mineralizações auríferas associadas, Região de Monte do Carmo-TO. Dissertação de Mestrado, Univ. Federal do Pará, 92 p.

Söderlund U. 1996. Conventional U-Pb dating versus singlezircon $\mathrm{Pb}$ evaporation dating of complex zircons from a pegmatite in the high-grade gneisses of southwestern Sweden: Lithos, 38:93-105.

Stacey J.S. \& Kramers J.D. 1975. Approximation of terrestrial lead isotope evolution by a two-stage model. Earth Planetary Sci. Letters, 26:207-221.

Streckeisen A. 1976. Plutonic rocks. Classification and nomenclature recommended by the IUGS Subcommission on the Systematic of Igneous Rocks.Geotimes, 18:26-36.

Thompson R.R. 1982. British tertiary volcanic province. Scott. Geolo., 18:89-107.

Whalen J.B., Currie K.L., Chappell B.W. 1987. A-type granites: geochemical characteristics, discrinination and petrogenesis. Contrib. Mineral. Petrol., 95:407-419.

Manuscrito ID 9099 Submetido em 17 de setembro de 2007 Aceito em 20 de junho de 2008 Sistema eletrônico de submissão 